\title{
Ignoring da Vinci and Darwin: The making of a better outlet valve
}

\author{
William M. DeCampli, MD, PhD
}

\author{
From the Department of Clinical Sciences, The University of Central Florida, College of Medicine, Orlando, Fla \\ Disclosures: Author has nothing to disclose with regard to commercial support. \\ Received for publication Aug 31, 2016; accepted for publication Sept 1, 2016; available ahead of print Oct 4, \\ 2016. \\ Address for reprints: William M. DeCampli, MD, PhD, The Heart Center at Arnold Palmer Hospital for Children \\ and the University of Central Florida College of Medicine, 50 W Sturtevant St, Orlando, FL 32806 (E-mail: \\ William.decampli@ucf.edu). \\ J Thorac Cardiovasc Surg 2017;153:387-8 \\ $0022-5223 / \$ 36.00$ \\ Copyright (c) 2016 by The American Association for Thoracic Surgery \\ http://dx.doi.org/10.1016/j.jtcvs.2016.09.013
}

What is the "perfect" heart valve? How many leaflets should it have? The Italian polymath, Leonardo da Vinci, addressed these questions almost 500 years ago. ${ }^{1}$ He said the 3-leaflet valve was clearly superior to the 4-leaflet valve, and by inference the 2-leaflet valve, because the 3-leaflet valve

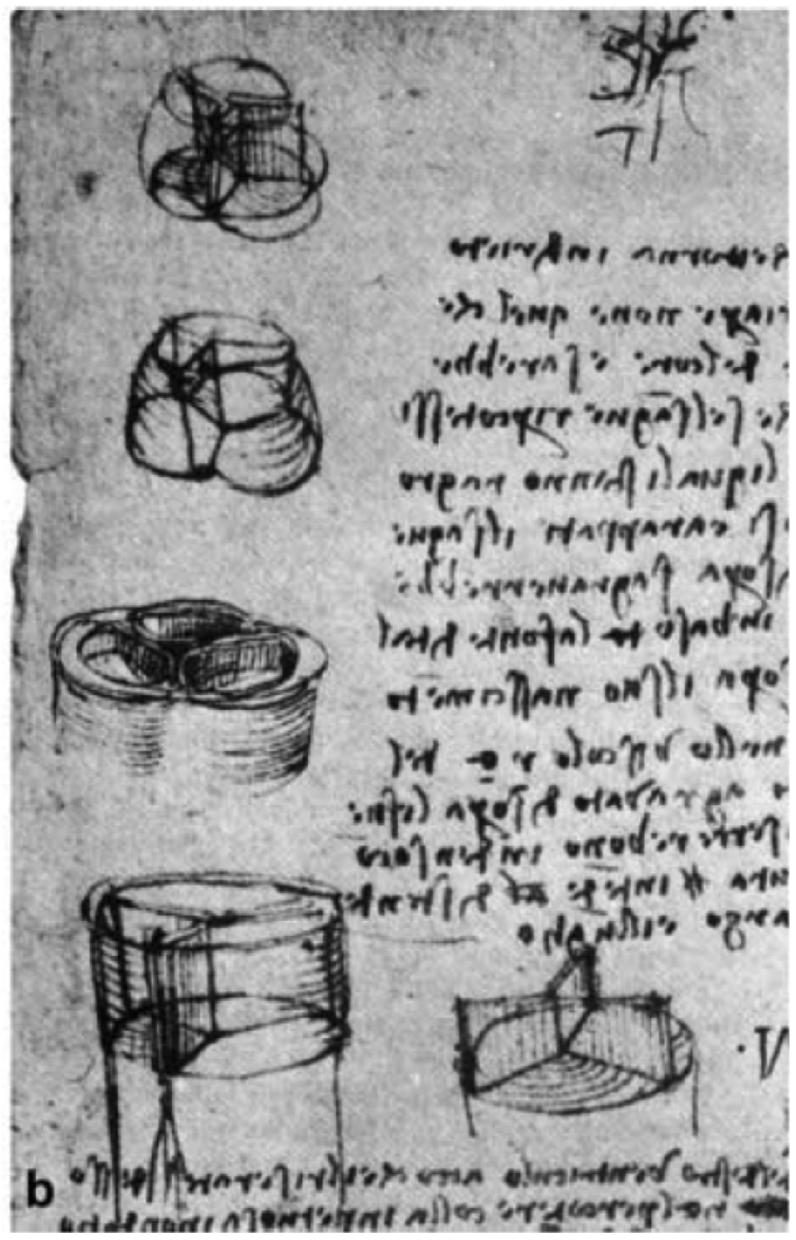

FIGURE 1. Design of 3-leaflet artificial heart valve for use in a glass model, by Leonardo da Vinci. (From RL19082 recto-by permission of The Royal Collection (C) 2002, Her Majesty Queen Elizabeth II.) (Figure 1).

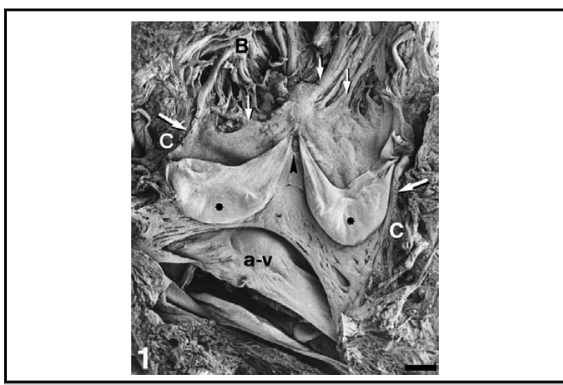

The outlet valve of this fish is bileaflet; should a pediatric prosthetic valve also be?

\section{Central Message}

A properly designed small valve prosthesis may be dilatable to adult size without regurgitation. The next challenge is to emulate the native leaflet's remarkable infrastructure and healing capacity.

See Article page 389

minimizes the stress on each leaflet base and hence the tendency for it to tear off of its attachment to the annulus

Although Leonardo's arguments were incomplete, the assertion that the 3-leaflet valve was superior persisted through the Renaissance and the age of Darwin, possibly because of the belief that humans were the "most highly evolved" species. Contemporary evolutionists, however, spurn such a belief. They believe that specific traits evolve to meet the environmental (or, in the case of the heart valve, hemodynamic) stresses particular to that species. For example, the teleosts (the class that includes most species of fish) exhibit a variety of number of leaflets associated with the conus (outlet) valves of their 2-chambered hearts. Whereas the dogfish (Scyliorhinus canicula) has a total of 7 leaflets, ${ }^{2}$ the gilthead seabream (Sparus auratus) has a 2-leaflet outlet valve ${ }^{3}$ (Figure 2). The porcine noncoronary cusp, in contrast to that of humans, is significantly smaller than both of the coronary cusps. In industrial applications, the so-called "check valve" (which is what the aortic valve really is) can be constructed in a variety of ways-from ball valves to butterfly valves to disk valves. Both benchtop and computational simulations show that all these valves work well in their particular settings.

In this issue of the Journal, Hammer and coworkers ${ }^{4}$ take a novel and creative twist on the question of the ideal valve. They ask, "What is the best prosthetic valve configuration 


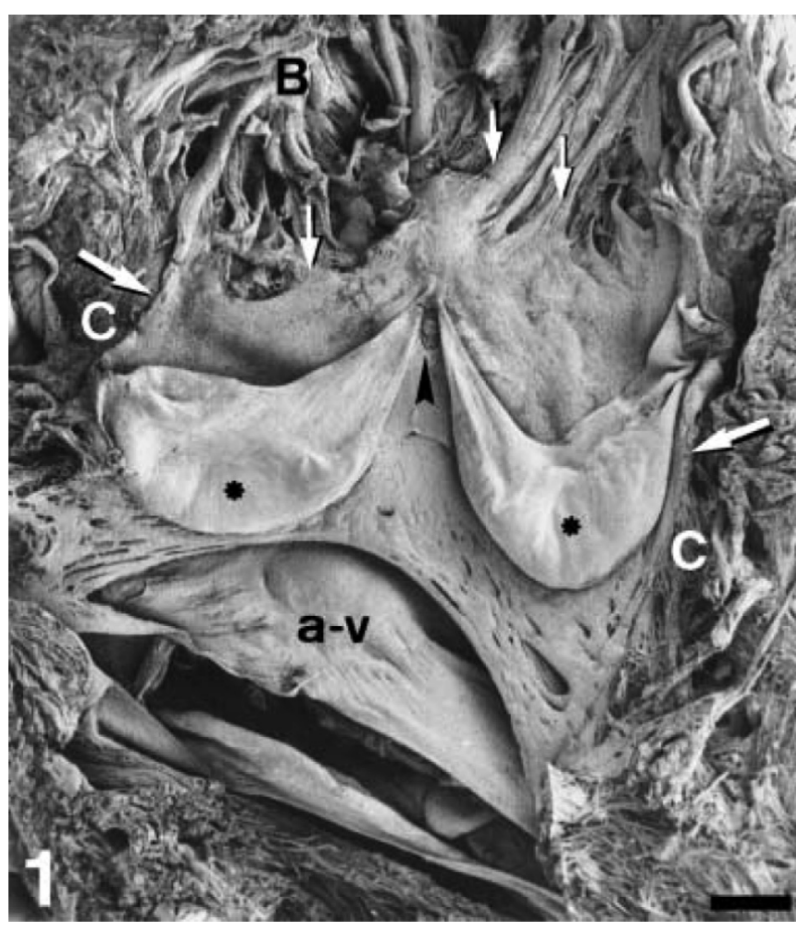

FIGURE 2. Scanning electron image of the 2-leaflet valve of the gilthead seabream. The black arrowhead shows a rudimentary posterior leaflet. The proximal portions of the leaflets (asterisks) are thicker than the edges. Small arrows show distal rim of the valve's fibrous "cylinder." Large arrows show the section of the cylinder. $B$ indicates the bulbus ridges; $C$ indicates conus myocardium; $a-v$ indicates atrioventricular valve. Scale $b a r=2 \mathrm{~mm}$. From Icardo et al. ${ }^{3}$ Used by permission of the publisher.

for a pediatric patient, such that it can be mechanically dilated to accommodate growth, yet remain competent for the longest time?" With an elegant geometric model and computational fluid dynamics, they conclude that the best valve is a 2-leaflet valve in which the ratio of both axial and free edge length to vessel diameter is greater than unity-unlike an aortic valve, but much like a venous valve. At an initial diameter of $12 \mathrm{~mm}$, the difference in "maximal dilatable diameter" between this valve and a conventional 3-leaflet semilunar valve was found to be significant$20 \mathrm{~mm}$ versus $13 \mathrm{~mm}$. Ideally, that would save a patient at least one operation in childhood. Overall, the hypothesis of Hammer and coworkers ${ }^{4}$ is soundly demonstrated and may serve as a backdrop for the novel design of smalloutlet prostheses.

The reality check, of course, is in what typically happens to leaflets, whether made of tissue or synthetic material. They deteriorate, for the simple reason that they are not native leaflets, and the valve becomes incompetent. In comparative anatomy, it is interesting to see how complex valve leaflets are. In birds and some fish, for example, myocardial tissue extends onto the leaflet bases. In some species, the degree of valve opening can thus be regulated to control ventricular afterload (and thus presumably ventricular-arterial coupling). ${ }^{2}$ In $S$ auratus, the leaflet extracellular matrix is rich in glycoconjugates, which are able to absorb water and regulate the viscoelastic properties of the leaflet so that recoil energy is optimally distributed. ${ }^{3}$ These features, in addition to the complex arrangement of the collagen and elastin fibers and the ability of the leaflet to remodel, contribute to optimal valve performance well beyond that provided by leaflet geometry alone. Nonetheless, demonstrating the ability to dilate a small, nongrowing valve to nearly adult size is an important step. Hammer and coworkers, ${ }^{4}$ by ignoring both da Vinci and Darwin, have provided a new direction for the challenging management of pediatric aortic and pulmonary valve disease.

\section{References}

1. Wells FC. The heart of Leonardo. London: Springer-Verlag; 2013:229-38.

2. Sans-Coma V, Gallego A, Muñoz-Chápuli R, De Andrés AV, Durán AC, Fernández B. Anatomy and histology of the cardiac conal valves of the adult dogfish (Scyliorhinus canicula). Anat Record. 1995;241:496-504.

3. Icardo JM, Schib JL, Ojeda JL, Durán AC, Guerrero A, Colvee E, et al. The conus valves of the adult gilthead seabream (Sparus auratus). J Anat. 2003;202:537-50.

4. Hammer PE, Roberts EG, Emani SM, del Nido PJ. Surgical reconstruction of semilunar valves in the growing child: should we mimic the venous valve? A simulation study. J Thorac Cardiovasc Surg. 2017;153:389-96. 